\title{
University Practice of Socialist Core Values Anime Piece of Research
}

\author{
Yanlin Tao \\ School Of Computer Science and Engineering of Qujing Normal University, QuJing, 655011, China. \\ 401004120@qq.com
}

Keywords: Socialist core values, the University, Practice

\begin{abstract}
The core values of socialism are the most basic and core values in the socialist value system and the value orientation of the development of the socialist social science. The core values of socialism play an important role in determining the direction and standard guiding the thinking and behavior of college students. This paper, through the production of an animated film that fulfills the core values of socialism of a college student, can deepen the education of the core values of school socialism, spread the positive energy, promote the construction of campus culture, and further guide the students positively Value orientation, moral education.
\end{abstract}

\section{The Significance of College Students' Practicing Socialist Core Value}

Core values, is a country and a nation in the long-term practice in the formation and development of a society must be long-term universal follow the basic values, is a national comprehensive strength and cohesion of the key. And actively cultivate and practice the socialist core values, is the core of the socialist core value system construction project ${ }^{[1]}$.

Former Soviet Union was the world "socialism" model, when the total economy is $60 \%-70 \%$ of the United States, people of their own core values are highly recognized and confident, with a strong sense of pride. Such a glorious 74-year-old socialist country collapsed overnight, for many reasons, the authoritative department, which is fatal because the original core values of the Soviet Union by the Western core values dominated, resulting in the confusion of people's thinking and The loss of faith, for the core values of the West, "peaceful evolution" provides the conditions and opportunities. At the moment, Western leaders have promoted Western values as an important part of their political program. In particular, every President of the United States in his speech, must speak of values. Yang to check ancient, down to view this. Core values have become the core of a country's soft power, the value of competition is an important area of comprehensive national strength competition.

The party and the state have always attached great importance to the cultivation of college students' values. In his speech at the symposium of Peking University, General Secretary Xi Jinping pointed out: "Contemporary college students are in the critical period of the formation of values. Therefore, they should attach importance to the cultivation of their values, because their value orientation plays a vital role in the future social value orientation. "Implementing the spirit of General Secretary Xi Jinping's important speech will require our contemporary college students to constantly enhance their sense of responsibility and mission, conscientiously study the socialist core values, conscientiously carry forward the traditional Chinese culture, adhere to the individual dream and the Chinese dream, The values of "freedom, equality, justice and the rule of law" at the social level and the values of "patriotism, devotion, integrity and friendliness" at the individual level are comprehensively practiced and practiced across the country at the national level. The values of "wealth, democracy, civilization and harmony" , And as a fundamental indicator of growth and success, in practice, constantly tempered themselves, broaden their horizons, temper character, and further improve their own quality and ideological and moral qualities, in order to achieve their all-round development.

\section{The innovation of this paper}

The innovation of this paper is to adopt the form of animation to promote campus culture behavior. This decision is determined by analyzing the structure of the Chinese animation audience. 
At present, people contact with the increasingly convenient animation products, the media more and more rich, animation is no longer a patent for young children, young people and adults are increasingly receiving love. According to the survey, the current domestic comics audience "absolute age" constitute, 13 years of age and below the total number of audiences accounted for $11 \%, 59 \%$ of the readers aged 14 to 17 years of age, over 18 readers accounted for 30 / RTI \& gt; ${ }^{2]}$ Moreover, animation products through the integration of images, sound and animation and other multimedia materials, to vivid expression of the subject, in terms of expression far superior to the dry terms of the text.

In September 2015, the Propaganda Department entrusted the School of Information Engineering, Tao Yanlin teacher to produce "Qujing Normal University students behavior norms animation", at present, the animation has been completed, and in the morning of September 12, 2016, in my school The deployment of the 2016 new student education and moral lectures premiere, play live good response, laughter, the students learn from the humorous animation film civilized behavior, Eliminate bad habits, striving to be a good education of civilized students. After the completion of the play, a guest of our school freshmen education of the Yunnan Provincial Party Committee Propaganda Department of the Office of the Deputy Director of the Office of the National People's Congress, Professor Ning Dejin, spoke highly of the film, fully affirmed the film form of propaganda, publicity, Stressed that this approach is worth to promote the province. After the meeting, many experts came to the venue to take the initiative to exchange views of the Ministry of Publicity animation comedy, asking to take the cartoon of the disc, until the third day after the meeting, there are phone calls to the Propaganda Department CD. In view of the above, the use of animation form of publicity, production and promotion of socialist core values is feasible and effective. Continue to use this kind of students loved, easy to promote the dissemination of the form, effectively deepen the school of socialist core values education, dissemination of positive energy, promote the construction of campus culture, and further positive guidance students value orientation, moral education.

\section{Research ideas and methods}

The development of the animation film technical route in five steps: the first step, through research, learning, collecting and collecting literature and other methods to collect themes, writing scripts. The second step, the use of Flash, Photoshop, Gold Wave, vivid and other software tools such as software, design and production of the main content of animation promo, screen sub-scenes produced. The third step, with vivid and AE software for post-production effects, animation animation of the main technical indicators is about 12 minutes, the output format is ". Avi". The fourth step, with the format factory software ". Avi" format of the promo into ".rmvb" format. The fifth step, the main use of Qujing Teachers College website (http://www.qjnu.edu.cn) to promote the film. R \& D of the technical route shown in Figure 1:

\section{Conclusions}

This project is based on the comprehensive construction of the socialist core value system, based on the great practice of socialism with Chinese characteristics, with the socialism with Chinese characteristics and the spirit of the 17th National Congress of the party as the guide to the healthy growth of college students The main line to college students agree with and practice the socialist core values as the perspective. The core values of socialism into the campus, into the classroom, into the mind, and effectively deepen the school's socialist core values of education, the dissemination of positive energy, and promote the construction of campus culture, to promote the construction of the core values of the socialist core values, Further positive guidance students values orientation, moral education. 


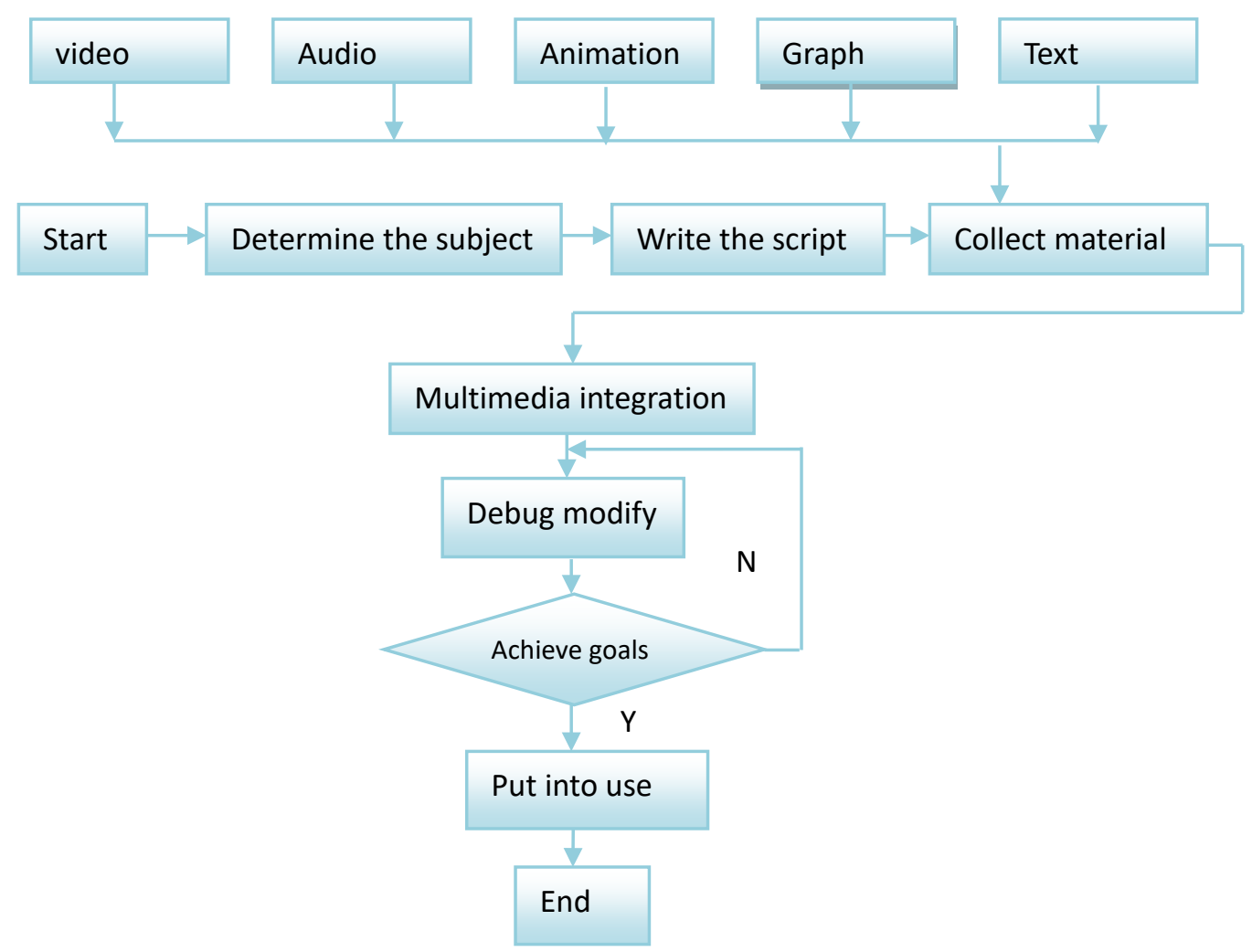

Figure 1 Multimedia application software flow chart

\section{Acknowledgment}

This paper is supported by three project funds:

1).Yunnan province education department scientific research fund project in general (project number: 2015y432);

2).National College Students Innovation and entrepreneurship training program of Ministry of Education of the People's Republic of China in 2015 (project number: 201510684001);

3).Qujing normal college scientific research fund special project(project number: 2016zx001).

\section{References}

[1] Shen Zhuanghai. The quasi-socialist core values cultivation and practice of the focus [N]. Guangming Daily, 2013-01-05 (1)

[2] WEI Lu, DING Fang-zhou. On the Transformation of Communication Research in the New Media Age [J]. Journal of Zhejiang University (Humanities and Social Sciences),2013(43):93-103.

[3] Wu Guijun, Shan Zhongji, Wu Rui, Li Qitao, Qu Yanpeng.Study on the path of "Chinese Dream" education for college students [J] .Livestock and Feed Science, 2016.37 (2): 86-87.

[4] Huang Dongxia. How to integrate the socialist core values into the whole process of ideological and political education [J]. Chongqing Radio and Television University, 2016 (28): 24-34.

[5] Yinghui, Liu Jianfeng .Analysis of adolescent cartoon preference and its industrial model [J]. Business Times, 2010 (02).

[6] HE Ye, YANG Jing, YANG Jiajia. Research on the Education of Socialist Core Values of Ethnic Minority College Students [J] .Chongqing and World, 2016 (08): 64-69.

[7] Liu Zheng.College students agree with and practice the socialist core values of [D]. Changsha: Central South University doctoral dissertation, 2012 